Article

\title{
Education and Disaster Vulnerability in Southeast Asia: Evidence and Policy Implications
}

\author{
Roman Hoffmann ${ }^{1,2, *(1)}$ and Daniela Blecha ${ }^{3}$ \\ 1 Potsdam Institute for Climate Impact Research, Telegrafenberg A56, 14473 Potsdam, Germany \\ 2 Wittgenstein Centre for Demography and Global Human Capital, Vienna Institute of Demography, \\ Austrian Academy of Sciences, Welthandelsplatz 2, 1020 Vienna, Austria \\ 3 Development and humanitarian affairs professional, Rue de l'Arbre Benit 70, 1050 Ixelles, Belgium; \\ daniela_blecha@hotmail.com \\ * Correspondence: roman.hoffmann@oeaw.ac.at
}

Received: 17 December 2019; Accepted: 4 February 2020; Published: 14 February 2020

\begin{abstract}
This article summarizes the growing theoretical and empirical literature on the impact of education on disaster vulnerability with a focus on Southeast Asia. Education and learning can take place in different environments in more or less formalized ways. They can influence disaster vulnerability as the capacity to anticipate, cope with, resist, and recover from natural hazard in direct and indirect ways. Directly, through education and learning, individuals acquire knowledge, abilities, skills and perceptions that allow them to effectively prepare for and cope with the consequences of disaster shocks. Indirectly, education gives individuals and households access to material, informational and social resources, which can help reducing disaster vulnerability. We highlight central concepts and terminologies and discuss the different theoretical mechanisms through which education may have an impact. Supportive empirical evidence is presented and discussed with a particular focus on the role of inclusiveness in education and challenges in achieving universal access to high-quality education. Based on situation analysis and best practice cases, policy implications are derived that can inform the design and implementation of education and learning-based disaster risk reduction efforts in the region.
\end{abstract}

Keywords: education; disaster vulnerability; disaster risk reduction; Southeast Asia; review; policy implications

\section{Introduction}

Who is vulnerable to natural disasters and other environmental hazards and to what extent are fundamental questions in vulnerability reduction efforts [1-3]. This article focuses on differential vulnerabilities to natural hazards in Southeast Asia and reviews evidence of the role of formal, non-formal, and informal education in influencing households' and communities' preparedness against and ability to cope with hazards and shocks. Education has been shown to be an important enabler of sustainable development in different contexts and with relevance for various development outcomes [4]. It is not only essential to poverty alleviation and economic growth, but can also enhance societies' adaptive capacity vis-à-vis future climate change [5-7]. As such, education, including both school-based and less formalized approaches, can also make an important contribution to reducing vulnerability to natural disasters and hazards, referring to the susceptibility of an individual, a community, assets or systems to the impacts of hazards [8].

The important role of education in disaster risk reduction and mitigation has been recognized in the Sendai Framework for Disaster Risk Reduction, the first major United Nations (UN) agreement of the Sustainable Development Agenda, which highlighted the need for population-wide resilience 
building and the enhancement of disaster preparedness for effective response and fast recovery, rehabilitation, and reconstruction. To achieve these aims, the framework underlines the importance "to promote national strategies to strengthen public education and awareness in disaster risk reduction, including disaster risk information and knowledge, through campaigns, social media and community mobilization, taking into account specific audiences and their needs" [9].

Despite improvements in national disaster risk reduction efforts in the Southeast Asian region, especially after major disaster events, such as the 2004 Indian Ocean Tsunami [10] or the 2013 Typhoon Haiyan in the Philippines [11], further steps have to be taken to prevent loss of life and major damages in the future. Often, disaster risk reduction measures undertaken at the national level alone are not enough to protect households and communities from the devastating impacts of natural hazards. Not only are public efforts challenged by addressing local needs and conditions, but it also takes some time for local governments and disaster-relief organizations to mobilize resources to an affected area once a disaster has occurred. In addition to national initiatives, increased local efforts are needed, involving the communities and individual households, to help withstand future shocks [12].

This article places a particular focus on the vulnerability to natural disasters and calamities. These are rapid-onset, extreme events that result from natural (e.g., hydrological, meteorological, geological or climatological) processes. Examples include floods, typhoons, volcanic eruptions, tsunamis, or earthquakes. Due to their limited predictability, natural disasters can cause severe loss of life and major damages to property. In order to prevent disastrous consequences, adequate preparation and the undertaking of precautionary measures is key.

In addition to community efforts, household preparedness measures, such as stockpiling of food and water, having a first aid kit in the home, or a family evacuation plan can help to mitigate the harmful consequences of disasters $[13,14]$. Despite the importance of individual preparedness, several studies report relatively low levels of disaster preparedness even in disaster prone areas [15]. In this context, education can help to raise awareness among households and promote the adoption of precautionary measures. It can furthermore support the provision of critical material and immaterial resources, required to prepare against and adapt to natural hazards adequately. Education can, hence, be a key element in disaster risk mitigation and help reducing vulnerabilities to disaster and other environmental hazards both on a household and community level $[7,16]$.

The remainder of this article is structured as follows: Section 2 introduces central concepts related to education and demographic differential vulnerabilities to natural hazards, followed by a review of the theoretical and empirical literature in Section 3. In particular, the review focuses on potential channels through which education can have an impact and related empirical evidence. Section 4 presents a situation analysis for the case of Southeast Asia and highlights major challenges in the education systems in the region that are of relevance for disaster vulnerability. Based on the findings, we showcase best practices of education policies and interventions that have been successfully implemented in the region and derive policy lessons for national and local disaster risk reduction efforts. The final section concludes with some final remarks and an outlook on future research.

\section{Central Concepts and Terminology}

We follow a broad definition of education as the process of facilitating the learning of knowledge, skills/competencies, values, beliefs and habits. People are constantly learning in different environments. Education can take place in formalized institutions, as well as in non-formal or informal settings. Formal education or learning refers to classroom-based education normally delivered in a systematic way by trained teachers in a structured environment, such as a school, college or university. This form of education is intentional and has specific pre-defined learning outcomes, which are transparently communicated to the learners.

Education, however, is not restricted to learning in the formal education system, but can take place in different environments outside the classroom. As we will show later, these often less institutionalized forms of information and knowledge dissemination can play a crucial role in reducing 
vulnerabilities to disasters. Organized and structured educational activities that take place outside the established formal school system are referred to as non-formal education $[17,18]$. These include community education or alternative learning programs, such as community-based disaster training and drills. Informal education, on the other hand, refers to learning through exchange with others and the enlargement of experiences. This less structured form of education includes social learning from peers or family members. In particular, knowledge, skills, values and beliefs obtained during childhood through parents and other close family members can be a crucial factor in influencing behavior later in life $[19,20]$.

Importantly, learned knowledge and skills are not always explicit to the learner, but can be tacit. Explicit knowledge can be clearly identified, accessed and verbalized. Tacit knowledge, on the other hand, is implicit [21,22]. It can be defined as knowledge, skills, ideas, and experiences that people have, but which they may not be consciously aware of and which can not necessarily be easily expressed or explained to others. This involves knowledge about how to perform certain activities, such as riding a bike or tying a shoe, or how to behave and react in certain situations. Tacit knowledge is typically learned through interactions with others and is, thus, closely connected to informal learning. Acquiring it requires practice and extensive social exchange. Forms of internalized knowledge and behavioral skills are of great importance for disaster prevention. Especially under stress or in life-threatening situations, humans tend to follow internalized heuristics, intuitions, and implicit knowledge and skills. These can be decisive for whether people take the right decisions and can mean the difference between life and death [23].

Disaster education or disaster resilience education, which is any form of learning about risks of environmental hazards and protective measures, should address both explicit, as well as tacit knowledge and skills. In the recent years, the field of disaster education has grown substantially, including new ways to prepare the public for disasters that go beyond school-based initiatives and public information campaigns, but also include more non-formal ways of learning, such as family and community learning activities and adult and senior citizen education. New technological advancements, such as social media and disaster apps, open further pedagogical space for learning and the dissemination of information and knowledge.

Vulnerability to environmental hazards is a function of a household's or community's susceptibility, sensitivity and adaptive capacity [24], which are influenced by physical, social, economic and environmental factors or processes. Susceptibility or exposure refers to the presence of people in places that are at risk of being adversely affected, while sensitivity relates to the degree to which a population group is negatively affected once a shock occurs. Adaptive capacity is the ability to cope with and adjust to consequences of natural hazards. Here, we consider all three aspects of vulnerability. Importantly, within societies, different population groups are characterized by a differential vulnerability, i.e., environmental hazards do not affect population groups equally. The degree to which a population group is vulnerable depends on social, economic, cultural, and political factors, which are often closely inter-linked with each other [8]. Socioeconomic inequalities play an important role with marginalized groups, women, young children and older people, as well as people with health problems or disabilities being particularly vulnerable to natural hazards $[25,26]$.

In this regard, resilience building on household and community level helps reducing vulnerabilities in advance. It is an important part of any disaster risk mitigation strategy. The term resilience refers to the household's or community's abilities and resources to adequately prepare for, mitigate and cope with disruptive changes and events that may occur in an unforeseen way. Various factors contribute to resilience, including not only economic, but also social, demographic and institutional factors. Among these, also education and the dissemination of knowledge and information can effectively contribute to resilience building efforts [27].

Vulnerability and resilience are both important for disaster risk reduction, which in the concept and practice of reducing disaster risks through systematic efforts, including the anticipation of future disaster risks, the reduction of existing exposures, hazards, and vulnerabilities, and the improving 
of resilience. The term risk refers to the potential loss of life, injury, or destroyed or damaged assets, due to natural hazards. It is determined probabilistically as a function of hazard, exposure and vulnerability $[3,28]$. Disaster education is an important vehicle of disaster risk reduction, allowing to disseminate information and knowledge and change behavioral intentions and actions in the form of a stepwise process.

\section{Theoretical Framework and Previous Literature}

\subsection{Education Effects: Understanding the Underlying Mechanisms}

Education can influence disaster vulnerability through various channels, which can be distinguished in direct and indirect effects. Figure 1 illustrates the different pathways in a schematic way. Importantly, here, we focus on all forms of education, be it formal, non-formal, or informal, which can take place in different environments. Primarily, these are expected to affect disaster vulnerability by positively influencing household and community resources (material, informational, and social), awareness and beliefs, and risk perceptions, which in turn affect the susceptibility, sensitivity and adaptive capacity as main vulnerability features. Often, the process of direct influence is stepwise, first changing available information and knowledge, then awareness and perceptions, and ultimately, behavioral intentions and actions of individuals [29].

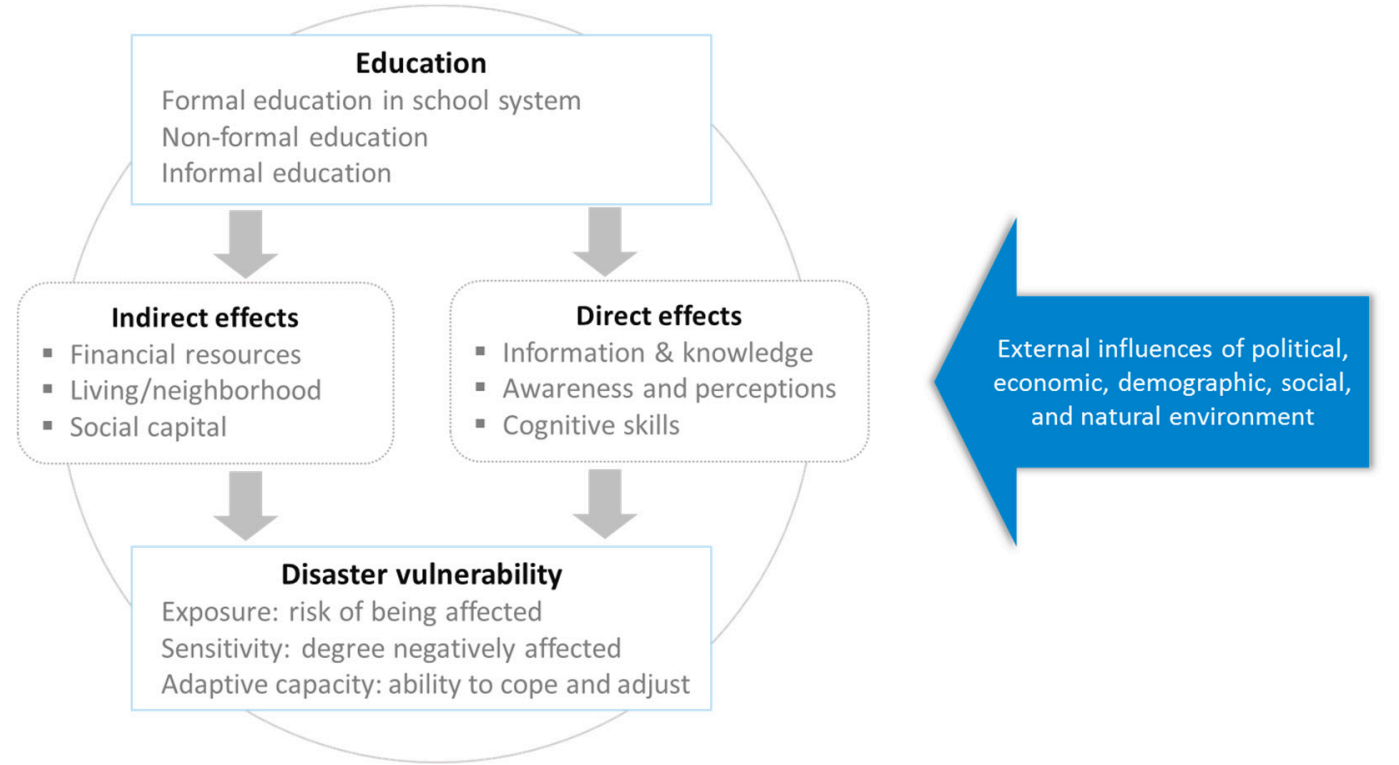

Figure 1. The conceptual relationship between education and disaster vulnerability.

First, directly, education gives individuals access to knowledge and information about threats, as well as about ways to adequately take measures against them. In particular, when it comes to preparing against a disaster, having comprehensive information is crucial. This includes information about the disaster risks in a community (e.g., where and when to expect a disaster), the adequacy of precautionary measures (e.g., stockpiling of food and emergency supplies), warning systems (e.g., about from where to receive further information), emergency plans and management (e.g., institutions providing support during a disaster), how to respond and behave during a disaster (e.g., where to look for shelter), and ways to cope with a disaster in the aftermath (e.g., when to return to the disaster-affected area). These are not only important for households, but also for entire communities, which require knowledge and information for informed decision-making and coordinated actions [23].

At the same time, individuals acquire skills and competencies through education that can help reduce their vulnerability to external shocks. For formal schooling, there is established evidence showing how schooling can positively affect cognitive skills, including complex cognitive reasoning, such as 
categorization, logical deduction and the solving of complex problems [30-34]. Such cognitive skills can be helpful in assessing the risks related to disaster threats and in finding adequate responses $[35,36]$.

Literacy skills obtained at school can also reduce disaster vulnerability. Literacy does not only refer to the ability to read and write, but also to understand information, such as warnings or recommendations [37,38]. Functional literacy refers to the ability of a person to "engage in all those activities in which literacy is required for effective functioning of his or her group and community and also for enabling him or her to continue to use reading, writing and calculation for his or her own and the community's development" [39]. Related to this concept, disaster literacy was proposed as a holistic description of an individual's ability to read, understand, and use the information to make informed decisions and follow instructions in the context of mitigating, preparing, responding, and recovering from a disaster [40].

Education could also directly benefit disaster preparation efforts by changing risk and time preferences, as well as the capacity to plan for the future. Recent evidence suggests that more educated people act more goal-oriented, being able to allocate resources better, and making more investments in financial, health or education for their future [41-43]. This could influence the adoption of such precautionary measures which require long term investments, such as purchasing disaster insurance.

In addition, education can indirectly influence disaster vulnerability by having a positive impact on household's access to economic and informational resources, their settlement decision, and their social capital. On average, individuals with higher formal education and higher education degrees receive greater earnings and have more possibilities to diversify their income in case one of their income sources can no longer be sustained because of a natural hazard [44,45]. In addition, they have more resources at their disposal to buffer the negative consequences of a shock. Greater economic resources also enable the better educated to undertake costly preparedness actions, such as structural adjustments in their housing or the purchase of insurance against disaster risks. They can also use their resources to relocate from risk zones, such as flooding areas, making them less likely to be directly exposed to and affected by the negative effects of disasters.

Numerous studies have shown that education is positively related to better access to informational resources, i.e., more sources and types of information [46-48]. This is partly due to greater knowledge about where to obtain information from and better resources and skills to receive information, such as better access to information and communication technologies. For instance, it has been shown that the level of formal education is highly correlated with access to weather forecasts and early warnings, allowing better educated individuals to respond faster and prepare against hazards [49,50].

Another important channel through which education may increase preparedness activities is via social capital, i.e., resources that can be accessed through the social networks of peers and kin [51,52]. Both formalized and less formalized forms of education can help people understand the importance of social ties in disaster preparation and adaptation. Individuals who regularly participate in social activities can benefit from an exchange of useful information and warnings. Indeed, there is evidence that social participation, strong family and community networks and high level of trust are positively associated with preparedness behavior [53-55].

Importantly, the different mentioned factors interact with each other in a complementary way. Having material resources alone is often not enough. Individuals can benefit from material resources only with a thorough understanding of how to put the resources to the greatest use. Likewise, without access to financial or social resources, it is impossible to adequately prepare against a disaster shock, even with knowledge and awareness of its potentially harmful consequences. These multidimensional and complex interactions between different factors make it difficult to tackle vulnerabilities without concomitantly addressing the different underlying factors. Likewise, the impact of education on disaster vulnerability is complex and depends on a variety of contextual factors which might moderate the relationships. 


\subsection{Empirical Evidence: Education Effects on Disaster Vulnerability}

There is a growing empirical literature addressing the question of how education affects disaster vulnerability and how it can be used to strengthen the resilience of households and communities. This section reviews selected findings from the literature related to the effects of different forms of education on vulnerability outcomes: Susceptibility, sensitivity and adaptive capacity. Where possible, we highlight, based on the conceptual model developed in the previous section, the channels through which education and learning may have an impact and why. In the literature, there is a clear focus on the effects of formalized education on vulnerability outcomes, which is also reflected in this review.

Commonly, it is households with lower socioeconomic status and lower education level who reside in high risk areas, whereas, higher education groups are more likely to live in low risk areas. The better educated have been shown to be also more likely to relocate if they find themselves in a risky location. This relocation can result from different risk perceptions, a greater awareness of the potential hazards, or greater resources, enabling them to move [6,56,57]. Also for short-term evacuations, Reference [58] show that better educated persons react most strongly to cyclone warnings and are the ones most likely to evacuate after receiving a warning.

During the pre-disaster phase, disaster mitigation measures and the undertaking of precautionary actions is important. Numerous studies report that education, be it general education or specific disaster training, increase individual and household preparedness, including preparedness for earthquakes [59], hurricanes [60-62], floods [63,64], tsunami [65], as well as general emergency preparedness [66,67]. Similar findings are reported not only on the individual, but also on the aggregate level in country isons [68].

References [12] and [65] showed for the Philippines and Thailand that individual and household education levels are positively correlated with the probability of a household having undertaken precautionary measures and being prepared against disasters. Interestingly, the authors show that households also learn from previous disasters. If a household was affected by a disaster in the past, its' preparedness levels increase substantially. Similar evidence has been reported for households in other countries, which have experienced floods, earthquakes, hurricanes and wildfires [15]. Although learning through experience is common, it is not an ideal way to promote household adoption of precautionary measures. Instead, educational initiatives can fill the gap leading to higher degrees of preparation, even if personal experiences with disasters are missing.

In the aftermath of a disaster, education can help people to cope with the events and to adapt to the changing environment. Using longitudinal representative data from the island of Sumatra, Indonesia, before and after the 2004 Indian Ocean tsunami, [69] showed a higher survival rate for better educated males, but not females, suggesting important interactions with the local social and cultural context. Although the authors do not find differences in the level of posttraumatic stress, the higher educated were better able to cope with the disaster in the long term. For instance, they were less likely to live in a camp or temporary housing, but rather stayed with family and friends, revealing the important role of social networks for recovery after a disaster event $[70,71]$. At the same time, the better educated were more effective in smoothing and stabilizing their consumption after the disaster shock, i.e., they were exposed to fewer fluctuations and instability, revealing a greater economic resilience to hazards. In another study about the 2004 disaster event in Indonesia, Reference [72] found lower levels of anxiety, affective disorders and posttraumatic stress among better educated survivors of the disaster, indicating a higher resilience in terms of psychosocial wellbeing. Similar findings have been reported for Thailand [73].

Aside from general formal education, various studies have reported positive effects of non-formal education initiatives, including community-based disaster training and drills. These have been shown to be effective in building local capacities and in raising awareness and resilience of communities [74,75]. [65], who conducted their study in risk areas in coastal Thailand, reported that households who participated in disaster training were more likely to undertake precautionary measures. The training were most effective for individuals with high education, suggesting interactions between different education forms. Despite the potential of directed/steered disaster risk training, 
studies also point to challenges and barriers in their implementation, such as inadequate communication, lack of integration with the communities, and non-inclusivity, which might serve as an explanation for why some studies do not find a benefit.

Education is not only of relevance for household vulnerability, but also for the vulnerability of entire communities. In fact, it has been found that living in a community with a higher level of education significantly increases preparedness actions [73]. This suggests there are knowledge spill-overs and skill exchange amongst community members. [12] suggested that non-formal or social learning in the affected communities play an important role. Households in a community can exchange their experiences - possibly after having experienced a disaster event together-and undertake effective joint actions to prepare against future disaster events. Such complementarities in the communities can generate positive spill-overs, and amplify the impact of education for the learners.

\section{Situation Analysis}

The foregoing review indicates that both school-based and other forms of education matter for reducing disaster vulnerabilities in high-risk environments. This section describes the situation in Southeast Asia and analyzes to what extent insights from the education and learning literature have found an entry in national disaster risk reduction efforts. In particular, we discuss challenges related to providing inclusive access to education for all.

The formal education system and institutions in Southeast Asia differ from country to country and are strongly shaped by the local context. The heterogeneities result in different needs and challenges which must be considered. Figure 2A shows educational trends in the region from 1950-2010 and Figure 2B shows for 2010 net-enrollment rates (NER), i.e., the total number of enrolled students in a relevant age group divided by the total population in that age group, in different grades for countries in Southeast Asia [76]. While net enrollment in primary grades is generally high across the region, substantial differences in the net enrollment rates for lower and upper secondary education can be observed with poorer countries showing on average lower enrollment levels.

\section{A. Educational Expansion 1950-2010}

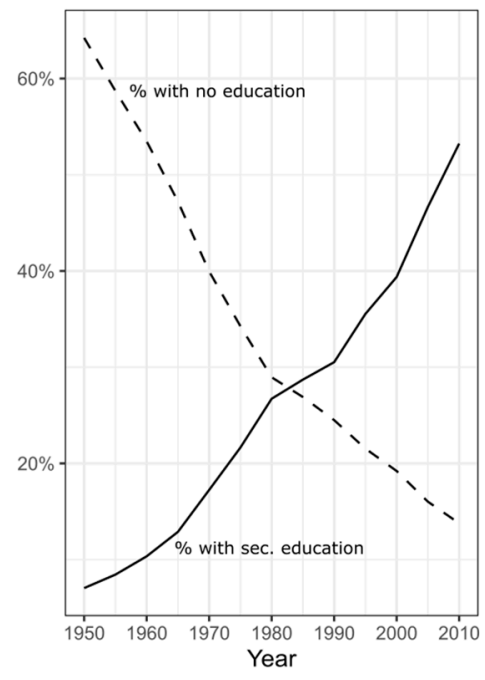

B. Enrollment Rates in Southeast Asia after 2010

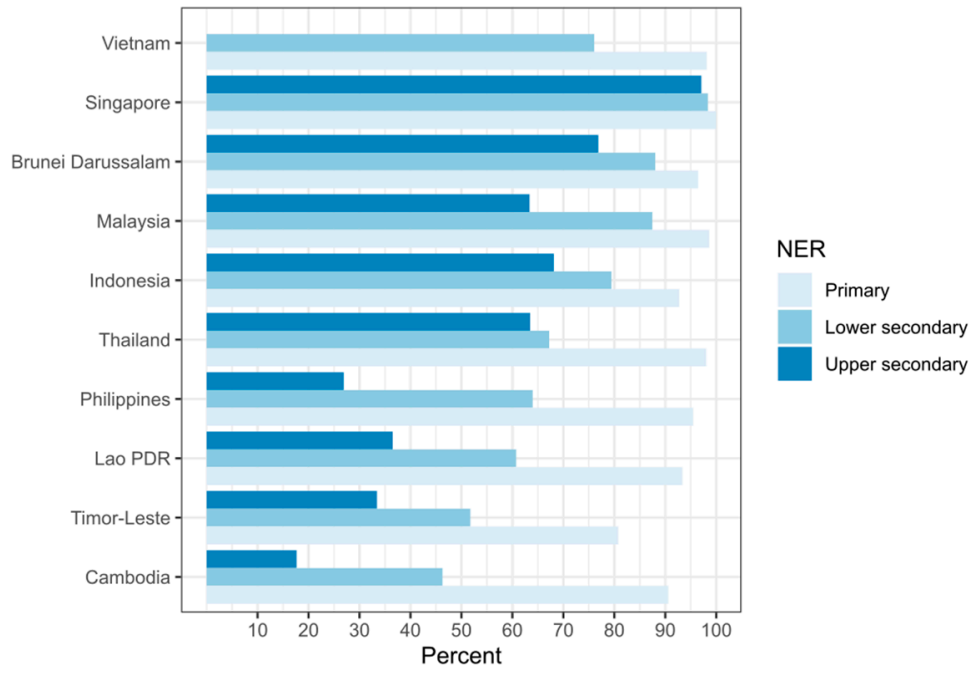

Figure 2. Panel A. Percent of population aged 15 and over with no education and with secondary education. Panel B. Net-enrollment rates in different grades for countries in Southeast Asia. Source A: Barro-Lee Educational Attainment Data [77], Singapore, Myanmar, and Timor Leste not included. Source B: World Bank Education Statistics (EdStats) 2019. Percentages calculated based on data from the last available year. NER, net-enrollment rates.

Importantly, educational resources and access to basic education are not equally distributed in the population, but are strongly influenced by social factors and circumstances, such as wealth, 
ethnicity and location [78]. Typically, people have little control over these factors, even though they play an important role in shaping their opportunities. Educational inequality refers to the unequal distribution of and access to academic resources. Poverty and marginalization are two of the major causes of educational inequalities, partly resulting from disadvantages in the education systems. Social inequalities are, hence, often multidimensional and interdependent with population groups being severely limited in their resources and capacities along several dimensions [79].

Figure 3 illustrates educational inequalities for selected countries in Eastern and Southeast Asia. It shows the lower secondary education completion rates for different wealth quintiles (poorest vs richest population groups). The black diamond shapes reflect the average completion rates. The length of the black lines indicates the amount of inequality in the countries. Data were obtained from the UNESCO World Inequality Database on Education, which reports combined averages for Eastern and Southeast Asia. Two countries from Eastern Asia that were included in the data, China and Mongolia, were added to the graph as additional reference points. Please note that the graph does not contain information for all countries in Southeast Asia, due to data availability.

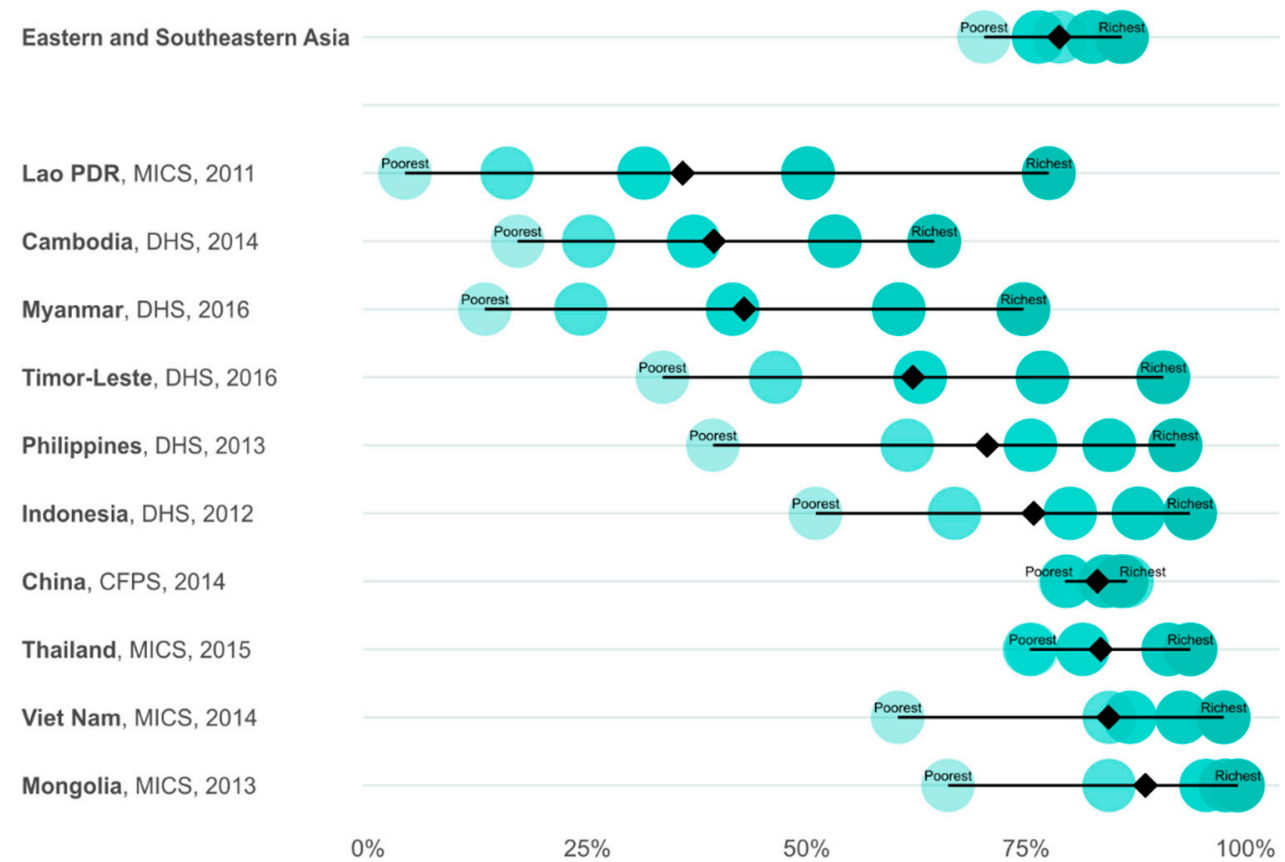

Figure 3. Educational inequalities in Eastern and Southeast Asia. The graph shows lower secondary education completion rates for different wealth quintiles. Diamond shapes reflect the average completion rates. Eastern Asian countries (China and Mongolia) included as additional reference points. Data based on household surveys: Multiple Indicator Cluster Surveys (MICS), Demographic and Health Survey (DHS), China Family Panel Survey (CFPS). The year refers to the year of data collection. Source: UNESCO, World Inequality Database on Education.

The graph reveals substantial educational inequalities in some Southeast Asian countries, such as Lao PDR, Cambodia, or Myanmar, where less than $25 \%$ of the poorest population group have completed lower secondary education. These inequalities can have important implications for disaster vulnerabilities [80-82]. As they are more likely to reside in high-risk areas, impoverished and marginalized communities are on average, more exposed to environmental hazards and lack material resources to prepare against hazardous events adequately. Their increased exposure and limited resources, together with their deprivation from education, lead to a substantial increase in disaster vulnerability among these population groups. In this regard, especially rural areas often face a disadvantage [8]. Rural populations, who have commonly worse access to education, are on average not only more exposed to natural hazards, they also depend more on the environment in their 
livelihoods. The important role of inequality for disaster vulnerability is, among others, acknowledged in the Sendai Framework for Disaster Risk Reduction, which promotes tackling the underlying disaster risk drivers, including poverty and inequality $[8,9]$.

Providing access to universal and high-quality education for all population groups can generate important spill-over effects for disaster risk reduction. In addition to providing universal access to formal education, non-formal education, such as disaster training, can also help to counteract existing gaps and serve as a short-term remedy addressing some of the challenges and risks faced by marginalized population groups.

In addition to social factors, gender and age are important demographic factors influencing educational attainment. Figure 4 shows literacy rates in Southeast Asia by age groups and sex serving as a proxy for education and learning outcomes. Please note that such outcomes are typically hard to capture in the form of simple indicators and the distinction by literacy level here serves mainly illustrative purposes to show how education outcomes can vary by sex and age groups.

Although there are very high literacy rates for both males and females in the age group 15-64, the rate is with $80 \%$ substantially lower in the oldest age category of $65+$ years. In this group, women have a disproportionally lower literacy compared to men, making them particularly vulnerable to environmental hazards. Increased levels of vulnerability among the elderly in general, and older women in particular, have been shown in different studies [15]. Such vulnerabilities result from complex interactions between environmental, social and demographic factors and can be reinforced through multiple sources.

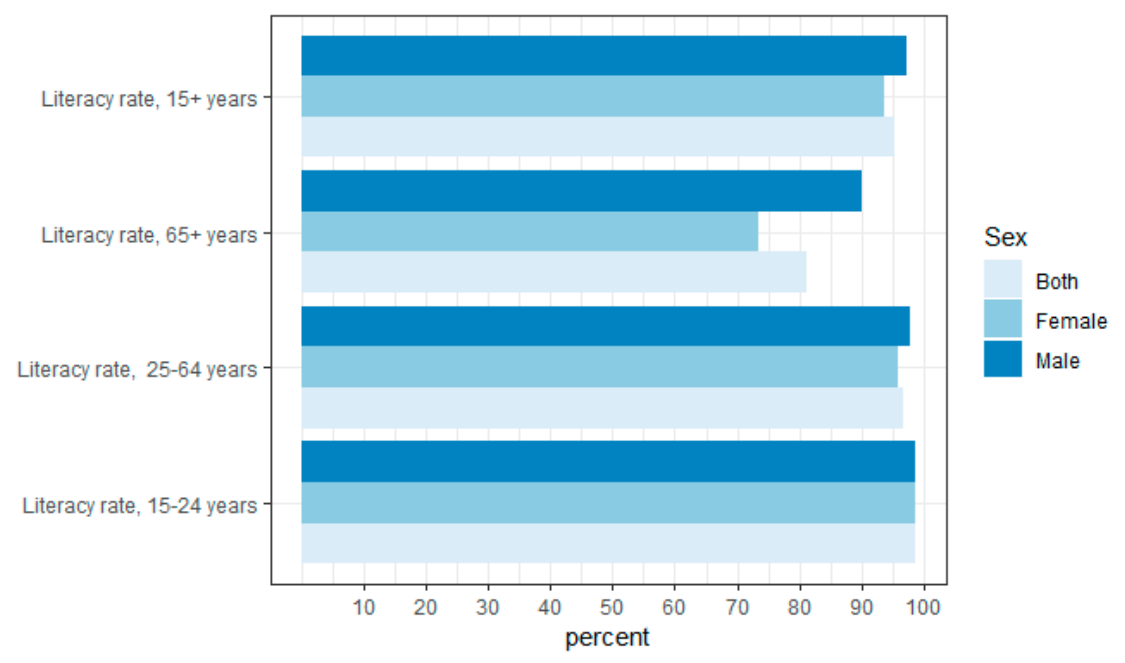

Figure 4. Literacy rates in Southeast Asia by age and sex. Source: World Bank Education Statistics (EdStats) 2019. Percentages calculated based on data from the last available year. Averages are based on the same sample of countries, as depicted in Figure 2.

Achieving universal education and fighting educational inequalities was made a top priority in the recently adopted Sustainable Development Agenda [83]. In addition, countries in Southeast Asia have embarked on reform processes to ensure inclusive and equitable quality education and promote lifelong learning opportunities for all. These reforms have resulted in improvements in access to universal education and educational attainments across all social groups. At the same time, major investments in school infrastructures and teachers led to higher education quality and better learning outcomes.

The role of education and learning has also been increasingly recognized in countries' disaster risk reduction efforts and strategies. Disaster training and drills have been successfully integrated into school curricula, for example, in the Philippines, Indonesia, and Thailand. Also, outside school, children and youth are increasingly involved in community efforts and political processes related to disaster risk reduction. Special disaster training program has been implemented that address vulnerable groups by 
taking into account the manifold interactions that create disaster vulnerabilities. For instance, special training have been developed to address senior citizens following a lifelong-learning approach and considering their particular needs and challenges.

Together with infrastructural measures on different levels, these interventions represent important steps to involve populations in disaster risk reduction efforts through education and learning. Despite the progresses, major challenges remain related to the inclusiveness of education and reducing disaster vulnerabilities along all dimensions. The following section presents best practice policy cases and highlight policy lessons of relevance for the Southeast Asian region.

\section{Policy Implications}

\subsection{Best Practices}

Formal learning pathways are important enablers for disaster resilience education. In the classroom setting, disaster risk reduction courses can either be offered as stand-alone courses or be integrated into the existing school curriculum. For the latter, it is necessary to undertake an audit of the existing curriculum and to appropriately define the entry points in the course of the curriculum adoption cycle for all subjects and age levels.

A promising example of formal disaster education is the ASEAN's "Safe Schools Initiative" (ASSI), which was launched in 2012 and promotes the inclusion of disaster education and training in national curricula across eight South East Asian countries, including Cambodia, Indonesia, Lao PDR, Malaysia, Myanmar, Philippines, Thailand and Vietnam [84]. In partnership with the ASEAN Member States and several non-governmental organizations, such as Plan International, Save the Children, World Vision and Mercy, and funding from the European Union and Australian Aid, the initiative aims at building disaster resilience of school communities through education. Pillar three of its framework, which sets the guidelines for any practical intervention, focuses on "risk reduction and resilience education" and is aligned with disaster management and education sector plans at national, sub-national and local levels.

A flagship program of the Safe Schools Initiative was launched in Malaysia in 2018, consisting of hands-on safety preparedness lessons for students and teachers to equip them with a basic understanding of disaster risks, as well as how to prepare for and act in the event of an emergency. While it intends to reach 1000 students and 100 teachers in 20 schools around the country, the material is only available in English and Bahasa Malaysia languages, which led to the exclusion of significant Mandarin-speaking population groups in some provinces of Malaysia. In Thailand, the initiative has succeeded in training more than 5000 pupils from 40 schools in disaster risk reduction, including the conduction of practical safe school exercises. According to involved teachers and civil society organizations, students successfully learnt how to save drowning people, as well as themselves.

The implementation of the initiative in the countries was confronted with various challenges, such as a limited willingness of teachers to engage, mostly due to the high workload and tight classroom schedule, as well as their own limited understanding of disaster risk reduction. Despite the challenges, the initiative is widely considered as a good policy intervention for formal disaster education, due to its' broad involvement of national governments, multilateral organizations and the civil society, ensuring comprehensive access to the target groups across an entire region and increasing sustainability of actions taken due to their alignment to other relevant national policies.

Aside from formal education, non-formal education interventions can serve as an important means in the field of disaster education. In this context, technology plays an increasingly important role. Humanitarian workers and people affected by disasters alike can be efficiently trained on disaster preparedness and management through e-learning methodologies, such as webinar-based coaching. Even more important, however, are tools and information which can be accessed on-the-go, for instance in the form of mobile applications. These can be highly effective as they are well-aligned with the mobile nature of disasters and rescue operations. One best practice example of the use of online 
technologies for relief work is the "Disaster Ready Initiative", which makes cutting-edge professional development resources available to relief and development workers and volunteers [85].

A further good example of non-formal learning measures in Southeast Asia has been piloted by UNESCO. Following the 2011 floods in Thailand, its Bangkok office launched in 2014 the mobile game application "Sai Fah: The Flood Fighter". It teaches players flood safety lessons as they are confronted with flood hazards [86]. Available in several languages, including Bahasa Indonesian, English, French and Thai languages, it had been downloaded over 100,000 times in 140 countries by late 2015. Due to high public demand, UNESCO Bangkok subsequently developed another promising mobile phone application, in response to tsunami and earthquake risks in the region. In collaboration with the Global Disaster Preparedness Centre (GDPC) and USAID and support from the Indonesian Red Cross, as well as the ASEAN Coordinating Centre for Humanitarian Assistance on Disaster Management (AHA Center), "Tanah: The Tsunami and Earthquake Fighter" was launched in 2015. The game provides the user with interactive challenges by following the fictional girl Tanah who learns how to prepare to and protect herself from tsunamis and earthquakes. According to the producers, the app allows users to learn key concepts of disaster risk reduction and enhance their hazard awareness.

As the applications developed by UNESCO have reached big numbers of mobile phone users, and considering that the consumption of online data continues to be on the rise among young people worldwide, such an intervention can be considered as effective for disaster resilience education. The authors furthermore assess its acceptance as high, particularly among children and adolescents, who may feel more appealed by learning through games than formal classroom teaching.

Besides formal and non-formal disaster education, informal interventions play an important role in strengthening people's preparedness and resilience. Informal education can be a rapid entry point for disaster education as it can be effectively implemented in engaging ways to introduce important knowledge, skills and competencies for students of all ages. Interventions can include creative educational materials, such as games, documentary and short videos, cultural and performing arts, such as songs, puppetry and improvisation theatre, as well as projects bringing students in contact with local communities and governments. These practical approaches can help foster the development of analytic and problem-solving skills among the learners.

In terms of informal education interventions, a large initiative using a peer-to-peer learning approach was implemented from 2011 to 2016 widely across South-East Asia by Plan International together with Australian Aid. The so-called "Child Centered Climate Change Adaptation (4CA)" program built the capacities of children about climate change related risks through the development and use of child-friendly education materials, such as children's books, posters, cartoons, animation films, as well as games. In a particularly innovative example in Indonesia, children were trained in photography skills to identify, map and record local knowledge useful for adaptation to climate change. In a second step, children were empowered to raise awareness within their communities on disaster risk reduction and climate change adaptation. Organization-internal lessons learnt assessment revealed that local communities in the most marginalized areas, including children, are receptive to increasing their knowledge about the causes and consequences of disasters. For the learning to be effective, it is essential to build on the people's understanding and link scientific information to local wisdom [87].

This program can be seen as a promising example, due to the low resources needed for the dissemination of knowledge, as it is members of the communities who share their learnings with others. Furthermore, it is an intervention which allows reaching out to people regardless of their educational level, including those who are not enrolled in any form of institutionalized education. Another convincing aspect of "Child Centered Climate Change Adaptation" is its strong recognition of and embedment into local realities, which can contribute to the stronger acceptance of the lessons taught.

\subsection{Policy Lessons}

The examples presented above, and particularly the Association of Southeast Asian Nations (ASEAN) regional "Safe School Initiative" highlight the importance of strong governmental involvement 
in disaster education. Indeed, the commitment of national authorities is key to ensure widespread access to society and especially to populations at risk. This is especially relevant in the context of formal education, considering that children from low-income households-which are more vulnerable to disasters-are likely to attend public schools. Only if the respective ministries of education broadly support the mainstreaming of disaster resilience education into national curricula, can disaster vulnerability be holistically addressed. It is, therefore, crucial that policy makers at all levels, including national, regional and local, take leadership in disaster education, and support any other actor in their efforts to build capacities for disaster preparedness.

Another key lesson learnt from the initiatives described in this paper is that there is no "one size fits all" solution to adequate disaster preparedness. As much as formal interventions are needed, their benefits, such as comprehensive geographic coverage of entire regions and contact to high numbers of students are only complementary to the distinct advantages of non-formal and informal educational measures. Non-formal disaster education is particularly valuable for capacity building with groups with low motivation or habituation for learning. Its' often playful features can attract those who may not pay attention to or actively engage in structured learning, as well as people with limited literacy. Furthermore, it is useful for the immediate dissemination of life-saving information, such as in the event of a rapidly approaching disaster.

Although informal education is similarly appropriate in the context of weak school performance and low reading and writing skills, due to its use of creative elements, it is further a powerful tool for its strong focus on local knowledge. Taking into account that informal disaster preparedness often involves a peer-to-peer component, as well as community-based learning, it represents a strong example for a bottom-up, grassroots-driven approach with high ownership of the learners. This, in turn, can strengthen the social acceptance of the educational interventions among the beneficiaries. Both non-formal and informal educational measures can moreover achieve better impacts in remote areas which are cut off from regular governmental interventions. Policy makers are, thus, recommended to design and support interventions which incorporate aspects of all ways of learning.

Inclusiveness is another crucial factor for effective and efficient disaster education. The Malaysian case study of Plan International's "Child Centered Climate Change Adaptation" project shows that linguistic diversity in South-East Asia has to be addressed appropriately to guarantee that "no one is left behind" in disaster preparedness efforts. Not translating educational material into minority languages can be perceived as discriminatory and contribute to a widening gap of those who can take life-saving measures in emergency situations thanks to previous training and access to information and those who lack the necessary knowledge. Any disaster education strategy should, hence, build on equality and inclusiveness as cornerstones taking the local context and all stakeholders in the communities into account.

\section{Conclusions}

This article summarizes the growing theoretical and empirical literature on the role of education for disaster vulnerability. Education, which can take place in different environments and which can be more or less formalized, can influence disaster vulnerability in direct and indirect ways. Directly, through education and learning, individuals acquire knowledge, abilities skills and perceptions that allow them to effectively prepare for and cope with the consequences of disasters. Indirectly, education gives individuals and households access to material, informational and social resources, which can help reduce their disaster vulnerability.

The connection between different forms of education and disaster vulnerability has been shown in various empirical studies both for the case of Southeast Asia and beyond. Better education levels were found to be positively related to various vulnerability outcomes, such as preparedness levels, reactions to early warnings, evacuations and relocation decisions, the adaptation to changing environmental conditions, and the ability to cope with the consequences of disasters in the aftermath. 
National risk reduction strategies have started to embrace insights from the education and learning literature to reduce the vulnerability of populations at risk. In many countries, disaster drills and courses have been integrated into national school curricula. Despite these advances, various challenges remain. Often, access to education and educational interventions is not inclusive, but strongly shaped by social, economic, political, and other factors. This results in populations benefiting differently from the positive effects of education with some groups having better access to information, knowledge and other resources.

More inclusive education and information dissemination strategies, possibly combined with the usage of modern information and communication technologies, can help address educational inequalities. In this regard, further research and data are needed in order to better understand how the resilience of highly marginalized communities can be most effectively increased. This includes highly vulnerable populations that have otherwise limited access to public schooling and education programs, such as refugee populations. Investments in universal education and the effective and inclusive dissemination of knowledge and information can help to make substantial contributions in disaster risk reduction efforts in the Southeast Asian region.

Author Contributions: Conceptualization, R.H. and D.B.; methodology, R.H.; software, R.H.; formal analysis, R.H.; writing-original draft preparation, R.H. and D.B.; writing—review and editing, R.H. and D.B.; visualization, R.H. All authors have read and agreed to the published version of the manuscript. Parts of this article will also be published in form of a book chapter [88].

Funding: This research was funded by the Austrian Science Fund, grant number Z171-G11. Further funding was provided by The International Climate Initiative (IKI: www.international-climate-initiative.com) and the German Federal Ministry for the Environment, Nature Conservation and Nuclear Safety (BMU) which supports the IKI on the basis of a decision adopted by the German parliament.

Conflicts of Interest: The authors declare no conflict of interest.

\section{References}

1. Adger, W.N.; Hughes, T.P.; Folke, C.; Carpenter, S.R.; Rockström, J. Social-Ecological Resilience to Coastal Disasters Social-Ecological Resilience to Coastal Disasters Social-Ecological Resilience to Coastal Disasters. Science 2012, 309, 1-6.

2. Adger, W.N. Vulnerability. Glob. Environ. Chang. 2006, 16, 268-281. [CrossRef]

3. Field, C.B.; Barros, V.; Stocker, T.F.; Dahe, Q.; Jon Dokken, D.; Ebi, K.L.; Mastrandrea, M.D.; Mach, K.J.; Plattner, G.K.; Allen, S.K.; et al. Managing the Risks of Extreme Events and Disasters to Advance Climate Change Adaptation; Cambrdige University Press: Cambridge, UK, 2012; ISBN 9781139177245.

4. Bengtsson, S.; Barakat, B.; Muttarak, R. The Role of Education in Enabling the Sustainable Development Agenda; Routledge: Abingon-on-Thames, UK, 2018.

5. Lutz, W.; Muttarak, R.; Striessnig, E. Universal education is key to enhanced climate adaptation. Science 2014, 346, 1061-1062. [CrossRef] [PubMed]

6. Muttarak, R.; Lutz, W. Is Education a Key to Reducing Vulnerability to Natural Disasters and hence Unavoidable Climate Change? Soc. 2014, 1, 48-55. [CrossRef]

7. Kagawa, F.; Selby, D. Ready for the Storm: Education for Disaster Risk Reduction and Climate Change Adaptation and Mitigation. J. Educ. Sustain. Dev. 2012, 6, 207-217. [CrossRef]

8. Twigg, J. Disaster risk reduction. Good Pract. Rev. 2015, 9, 1-382. Available online: https://goodpracticereview. org/ (accessed on 4 February 2020).

9. UNDRR. Sendai Framework for Disaster Risk Reduction 2015-2030. Available online: https://www.undrr.org/ (accessed on 4 February 2020).

10. Birkmann, J. Assessing Vulnerability Before, During and After a Natural Disaster in Fragile Regions; UNU WIDER Working Paper 50/2008; UNU WIDER: Helsinki, Finland, 2008.

11. Lagmay, A.M.F.; Agaton, R.P.; Bahala, M.A.C.; Briones, J.B.L.T.; Cabacaba, K.M.C.; Caro, C.V.C.; Dasallas, L.L.; Gonzalo, L.A.L.; Ladiero, C.N.; Lapidez, J.P.; et al. Devastating storm surges of Typhoon Haiyan. Int. J. Disaster Risk Reduct. 2015, 11, 1-12. [CrossRef] 
12. Hoffmann, R.; Muttarak, R. Learn from the Past, Prepare for the Future: Impacts of Education and Experience on Disaster Preparedness in the Philippines and Thailand. World Dev. 2017, 96, 32-51. [CrossRef]

13. Shreve, C.M.; Kelman, I. Does mitigation save? Reviewing cost-benefit analyses of disaster risk reduction. Int. J. Disaster Risk Reduct. 2014, 10, 213-235. [CrossRef]

14. van der Keur, P.; van Bers, C.; Henriksen, H.J.; Nibanupudi, H.K.; Yadav, S.; Wijaya, R.; Subiyono, A.; Mukerjee, N.; Hausmann, H.J.; Hare, M.; et al. Identification and analysis of uncertainty in disaster risk reduction and climate change adaptation in South and Southeast Asia. Int. J. Disaster Risk Reduct. 2016, 16, 208-214. [CrossRef]

15. Kohn, S.; Eaton, J.L.; Feroz, S.; Bainbridge, A.A.; Hoolachan, J.; Barnett, D.J. Personal disaster preparedness: An integrative review of the literature. Disaster Med. Public Health Prep. 2012, 6, 217-231. [CrossRef] [PubMed]

16. Tatebe, J.; Mutch, C. Perspectives on education, children and young people in disaster risk reduction. Int. J. Disaster Risk Reduct. 2015, 14, 108-114. [CrossRef]

17. Werquin, P. Recognising Non-Formal and Informal Learning: Outcomes, Policies and Practices; OECD Publishing: Paris, France, 2010; ISBN 9789264063853.

18. Singh, M. Global Perspectives on Recognising Non-formal and Informal Learning: Why Recognition Matters; Springer: New York, NY, USA, 2016; ISBN 978-3-319-15277-6.

19. Richardson, L.D.; Wolfe, M. Principles and Practice of Informal Education; Routledge: London, UK; New York, NY, USA, 2001.

20. Marsick, V.J.; Watkins, K.E. Informal and Incidental Learning. New Dir. Adult Contin. Educ. 2002, 2001, 25-34. [CrossRef]

21. Nonaka, I.; von Krogh, G. Perspective-Tacit Knowledge and Knowledge Conversion: Controversy and Advancement in Organizational Knowledge Creation Theory. Organ. Sci. 2009, 20, 481-683. [CrossRef]

22. Linde, C. Narrative and social tacit knowledge. J. Knowl. Manag. 2001, 5, 160-171. [CrossRef]

23. Weichselgartner, J.; Pigeon, P. The Role of Knowledge in Disaster Risk Reduction. Int. J. Disaster Risk Sci. 2015, 6, 107-116. [CrossRef]

24. Contribution of Working Groups I, II and III to the Fifth Assessment Report of the Intergovernmental Panel on Climate Change. In IPCC Climate Change 2014: Synthesis Report; IPCC: Geneva, Switzerland, 2014; ISBN 9789291691432.

25. Zagheni, E.; Muttarak, R.; Striessnig, E. Differential mortality patterns from hydro-meteorological disasters: Evidence from cause-of-death data by age and sex. Vienna Yearb. Popul. Res. 2015, 13, 47-70.

26. Muttarak, R.; Lutz, W.; Jiang, L. Introduction: What can demographers contribute to the study of vulnerability? Vienna Yearb. Popul. Res. 2015, 13, 1-13.

27. Paton, D.; Johnston, D. Disasters and communities: Vulnerability, resilience and preparedness. Disaster Prev. Manag. An Int. J. 2001, 10, 270-277. [CrossRef]

28. UNDRR. UNISDR Terminology on Disaster Risk Reduction; UNDRR: Geneva, Switzerland, 2009; Available online: https://www.undrr.org/publication/2009-unisdr-terminology-disaster-risk-reduction (accessed on 4 February 2020).

29. Ajzen, I. The theory of planned behaviour. Organ. Behav. Hum. Decis. Process. 1991, 50, 179-211. [CrossRef]

30. Blair, C.; Gamson, D.; Thorne, S.; Baker, D. Rising mean IQ: Cognitive demand of mathematics education for young children, population exposure to formal schooling, and the neurobiology of the prefrontal cortex. Intelligence 2005, 33, 93-106. [CrossRef]

31. Ceci, S.J. How much does schooling influence general intelligence and its cognitive components? A reassessment of the evidence. Dev. Psychol. 1991, 27, 703-722. [CrossRef]

32. Lee, J.J. Review of intelligence and how to get it: Why schools and cultures count. Intelligence 2010, 48, 247-255.

33. Eslinger, P.J.; Blair, C.; Wang, J.L.; Lipovsky, B.; Realmuto, J.; Baker, D.; Thorne, S.; Gamson, D.; Zimmerman, E.; Rohrer, L.; et al. Developmental shifts in fMRI activations during visuospatial relational reasoning. Brain Cogn. 2009, 69, 1-10. [CrossRef] [PubMed]

34. Quartz, S.R.; Sejnowski, T.J. The neural basis of cognitive development: A constructivist manifesto. Behav. Brain Sci. 1997, 20, 537-596. [CrossRef] [PubMed]

35. de Bruin, W.; Parker, A.M.; Fischhoff, B. Individual differences in adult decision-making competence. J. Pers. Soc. Psychol. 2007, 92, 938-956. [CrossRef] 
36. Peters, E.; Västfjäll, D.; Slovic, P.; Mertz, C.K.; Mazzocco, K.; Dickert, S. Numeracy and decision making. Psychol. Sci. 2006, 17, 407-413. [CrossRef]

37. Birru, M.S.; Monaco, V.M.; Charles, L.; Drew, H.; Njie, V.; Bierria, T.; Detlefsen, E.; Steinman, R.A. Internet usage by low-literacy adults seeking health information: An observational analysis. J. Med. Internet Res. 2004, 6, e25. [CrossRef]

38. Friedman, D.B.; Tanwar, M.; Richter, J.V.E. Evaluation of online disaster and emergency preparedness resources. Prehosp. Disaster Med. 2008, 23, 438-446. [CrossRef]

39. UNESCO. Functional Literacy. Available online: http://uis.unesco.org/node/334638 (accessed on 4 February 2020).

40. Brown, L.M.; Haun, J.N.; Peterson, L. A proposed disaster literacy model. Disaster Med. Public Health Prep. 2014, 8, 267-275. [CrossRef]

41. Chew, S.; Heckman, J.; Yi, J.; Zhang, J.; Zhong, S. Education and preferences: Experimental Evidence from Chinese Adult Twins; University of Chicago: Chicago, IL, USA, 2010.

42. Oreopoulos, P.; Salvanes, K.G. Priceless: The Nonpecuniary Benefits of Schooling. J. Econ. Perspect. 2011, 25, 159-184. [CrossRef]

43. Grossman, M. Education and Nonmarket Outcomes. In Handbook of the Economics of Education; Hanushek, E., Welch, F., Eds.; Elsevier: Amsterdam, the Netherlands, 2006; pp. 577-633. ISBN 9780444513991.

44. Card, D. The causal effect of education on earnings. In Handbook of Labor Economics; Ashenfelter, O., Card, D., Eds.; Elsevier: Amsterdam, the Netherlands, 1999; pp. 1801-1863. ISBN 9780444501875.

45. Heckman, J.J.; Humphries, J.E.; Veramendi, G. Returns to Education: The Causal Effects of Education on Earnings, Health, and Smoking. J. Polit. Econ. 2018, 126, 197-246. [CrossRef] [PubMed]

46. Cotten, S.R.; Gupta, S.S. Characteristics of online and offline health information seekers and factors that discriminate between them. Soc. Sci. Med. 2004, 59, 1795-1806. [CrossRef] [PubMed]

47. Neuenschwander, L.M.; Abbott, A.; Mobley, A.R. Assessment of low-income adults' access to technology: Implications for nutrition education. J. Nutr. Educ. Behav. 2012, 44, 60-65. [CrossRef]

48. Wen, L.M.; Rissel, C.; Baur, L.A.; Lee, E.; Simpson, J.M. Who is NOT likely to access the Internet for health information? Findings from first-time mothers in southwest Sydney, Australia. Int. J. Med. Inform. 2011, 80, 406-411. [CrossRef]

49. Xiao, C.; McCright, A.M. Environmental concern and sociodemographic variables: A study of statistical models. J. Environ. Educ. 2007, 38, 3-14. [CrossRef]

50. Rodriguez, H.; Diaz, W.; Santos, J.M.; Aguirre, B.E. Communicating Risk and Uncertainty: Science, Technology, and Disasters at the Crossroads. In Handbook of Disaster Research; Rodriguez, H., Quarantelli, E.L., Dynes, R.R., Eds.; Springer: New York, NY, USA, 2007; pp. 476-488.

51. Huang, J.; van den Brink, H.; Groot, W. A meta-analysis of the effect of education on social capital. Econ. Educ. Rev. 2009, 28, 454-464. [CrossRef]

52. Lake, R.L.D.; Huckfeldt, R. Social capital, social networks, and political participation. Polit. Psychol. 1998, 19, 567-584. [CrossRef]

53. Kirschenbaum, A. Families and Disaster Behavior: A Reassessment of Family Preparedness. Int. J. Mass Emerg. Disasters 2006, 24, 111-143.

54. Solberg, C.; Rossetto, T.; Joffe, H. The social psychology of seismic hazard adjustment: Re-evaluating the international literature. Nat. Hazards Earth Syst. Sci. 2010, 10, 1663-1677. [CrossRef]

55. Witvorapong, N.; Muttarak, R.; Pothisiri, W. Social participation and disaster risk reduction behaviors in tsunami prone areas. PLoS ONE 2015, 10, 1-20. [CrossRef] [PubMed]

56. Wamsler, C.; Brink, E.; Rentala, O. Climate change, adaptation, and formal education: The role of schooling for increasing societies' adaptive capacities in El Salvador and Brazil. Ecol. Soc. 2012, 17, 2-20. [CrossRef]

57. KC, S. Community vulnerability to floods and landslides in Nepal. Ecol. Soc. 2013, 18, 8 .

58. Sharma, U.; Patwardhan, A.; Patt, A.G. Education as a determinant of response to cyclone warnings: Evidence from coastal zones in India. Ecol. Soc. 2013, 18, 18. [CrossRef]

59. Russell, L.A.; Goltz, J.D.; Bourque, L.B. Preparedness and Hazard Mitigation Actions before and after Two Earthquakes. Environ. Behav. 1995, 27, 744-770. [CrossRef]

60. Baker, E.J. Household preparedness for the Aftermath of Hurricanes in Florida. Appl. Geogr. 2011, 31, 46-52. [CrossRef]

61. Norris, F.H.; Smith, T.; Kaniasty, K. Revisiting the experience-behavior hypothesis: The effects of Hurricane Hugo on hazard preparedness and other self-protective acts. Basic Appl. Soc. Psych. 1999, 21, 37-47. 
62. Reininger, B.M.; Rahbar, M.H.; Lee, M.J.; Chen, Z.; Alam, S.R.; Pope, J.; Adams, B. Social capital and disaster preparedness among low income Mexican Americans in a disaster prone area. Soc. Sci. Med. 2013, 83, 50-60. [CrossRef] [PubMed]

63. Lave, T.R.; Lave, L.B. Public Perception of the Risks of Floods: Implications for Communication. Risk Anal. 1991, 11, 255-267. [CrossRef]

64. Thieken, A.H.; Kreibich, H.; Müller, M.; Merz, B. Coping with floods: Preparedness, response and recovery of flood-affected residents in Germany in 2002. Hydrol. Sci. J. 2007, 52, 1016-1037. [CrossRef]

65. Muttarak, R.; Pothisiri, W. The role of education on disaster preparedness: Case study of 2012 Indian Ocean earthquakes on Thailand's Andaman coast. Ecol. Soc. 2013, 18, 51. [CrossRef]

66. Al-Rousan, T.M.; Rubenstein, L.M.; Wallace, R.B. Preparedness for natural disasters among older US adults: A nationwide survey. Am. J. Public Health 2014, 104, 506-511. [CrossRef] [PubMed]

67. Smith, D.L.; Notaro, S.J. Personal emergency preparedness for people with disabilities from the 2006-2007 Behavioral Risk Factor Surveillance System. Disabil. Health J. 2009, 2, 86-94. [CrossRef] [PubMed]

68. Pichler, A.; Striessnig, E. Differential vulnerability to hurricanes in Cuba, Haiti, and the Dominican Republic: The contribution of education. Ecol. Soc. 2013, 18. [CrossRef]

69. Frankenberg, E.; Sikoki, B.; Sumantri, C.; Suriastini, W.; Thomas, D. Education, vulnerability, and resilience after a natural disaster. Ecol. Soc. 2013, 18, 16. [CrossRef]

70. Marín, A.; Bodin, Ö.; Gelcich, S.; Crona, B. Social capital in post-disaster recovery trajectories: Insights from a longitudinal study of tsunami-impacted small-scale fisher organizations in Chile. Glob. Environ. Chang. 2015, 35, 450-462. [CrossRef]

71. Guarnacci, U. Joining the dots: Social networks and community resilience in post-conflict, post-disaster Indonesia. Int. J. Disaster Risk Reduct. 2016, 16, 180-191. [CrossRef]

72. Irmansyah, I.; Dharmono, S.; Maramis, A.; Minas, H. Determinants of psychological morbidity in survivors of the earthquake and tsunami in Aceh and Nias. Int. J. Ment. Health Syst. 2010, 4, 1-10. [CrossRef]

73. Garbero, A.; Muttarak, R. Impacts of the 2010 droughts and floods on community welfare in rural Thailand: Differential effects of village educational attainment. Ecol. Soc. 2013, 18, 27. [CrossRef]

74. Allen, K.M. Community-based disaster preparedness and climate adaptation: Local capacity-building in the Philippines. Disasters 2006, 30, 81-101. [CrossRef]

75. Karanci, A.N.; Aksit, B.; Dirik, G. Impact of a Community Disaster Awareness Training Program in Turkey: Does it Influence Hazard-Related Cognitions and Preparedness Behaviors. Soc. Behav. Personal. Int. J. 2006, 33, 243-258. [CrossRef]

76. World Bank. World Development Indicators; World Bank: Washington, DC, USA, 2019.

77. Barro, R.; Lee, J.-W. A New Data Set of Educational Attainment in the World, 1950-2010. J. Dev. Econ. 2013, 104, 184-198. [CrossRef]

78. Orfield, G.; Lee, C. Why Segregation Matters: Poverty and Educational Inequality; Civil Rights Project: Cambridge, MA, USA, 2005. Available online: https://eric.ed.gov/?id=ED489186 (accessed on 4 February 2020).

79. Seth, S.; Santos, M.E. Multidimensional Inequality and Human Development; OPHI Working Paper 114; Oxford Poverty \& Human Development Initiative: Oxford, UK, 2018.

80. Bullard, R.D. Differential vulnerabilities: Environmental and economic inequality and government response to unnatural disasters. Soc. Res. (NY). 2008, 75, 753-784.

81. Bolin, B.; Kurtz, L.C. Race, Class, Ethnicity, and Disaster Vulnerability. In Handbook of Disaster Research; Rodríguez, H., Donner, W., Trainor, J., Eds.; Springer: Cham, Switzerland, 2018.

82. Donner, W.; Rodriguez, H. Population Composition, Migration and Inequality: The Influence of Demographic Changes on Disaster Risk and Vulnerability. Soc. Forces 2008, 87, 1089-1114. [CrossRef]

83. UN. Transforming our World: The 2030 Agenda for Sustainable Development; United Nations General Assembly: New York, USA, 2015.

84. ASEAN. Safe School Initiative. Available online: https://aseansafeschoolsinitiative.org/ (accessed on 4 February 2020).

85. Cornerstone on Demand Foundation Disaster Ready Initiative. Available online: https://www.disasterready. org/ (accessed on 4 February 2020).

86. UNESCO. Sai Fah: The Flood Fighter. Available online: https://bangkok.unesco.org/content/sai-fah-floodfighter (accessed on 4 February 2020). 
87. Plan International \& Australian Aid Child Centred Climate Change Adaptation (4CA), Act to Adapt, The Next Generation Leads the Way. Available online: https://plan-international.org/publications/act-adaptchild-centred-climate-change-adaptation (accessed on 4 February 2020).

88. Hoffmann, R.; Blecha, D. Education and Disaster Vulnerability in Southeast Asia: Evidence and Policy Implications. In Resistance, Resilience, and Recovery from Disasters: Mental Health and Psychosocial Support Perspectives from Southeast Asia; Waelde, L., Hechanova, R.H., Eds.; Emerald Publishing: Bingley, UK, 2020.

(c) ( (C) 2020 by the authors. Licensee MDPI, Basel, Switzerland. This article is an open access article distributed under the terms and conditions of the Creative Commons Attribution (CC BY) license (http://creativecommons.org/licenses/by/4.0/). 